\title{
A construção de uma elite burocrática: o caso dos gestores governamentais em Mato Grosso
}

\author{
Julio Cezar de Lara \\ Governo do Estado de Mato Grosso \\ Kelliton Rodrigues de Souza \\ Governo do Estado de Mato Grosso \\ Maria Stella Lopes Okajima Conselvan \\ Governo do Estado de Mato Grosso \\ Vinícius de Carvalho Araújo \\ Governo do Estado de Mato Grosso
}

A partir do relatório Rouanet (1982), emergem reflexões sobre a necessidade de um novo perfil de burocrata num contexto de globalização econômica e de reforma do Estado brasileiro. A redemocratização e, consequentemente, a entrada de novos atores no processo decisório demonstraram a necessidade de profissionalização da alta burocracia, para geração de valor dos serviços públicos. O presente trabalho tem como objetivo apresentar uma descrição da trajetória da carreira dos gestores governamentais de Mato Grosso, que é uma das mais antigas do País e ainda não há na literatura trabalhos publicados sobre o conteúdo aqui apresentado. Metodologicamente, a pesquisa foi de natureza descritiva e baseou-se na coleta de dados em referenciais teóricos e legais para, em seguida, ser feita uma análise dos dados coletados. Concluiu-se observando que a carreira de Gestor Governamental de Mato Grosso tende à consolidação, demonstrada pelo número de servidores ocupantes do cargo e papel em reconhecimento, para a efetividade das políticas públicas do Estado do Mato Grosso.

Palavras-chave: reforma administrativa, alta administração pública, carreira pública, capacitação profissional, administração regional, estudo de caso

[Artigo recebido em maio de 2014. Versão final em outubro de 2014.] 
La construcción de una élite burocrática: el caso de los administradores del gobierno de Mato Grosso

Desde el informe Rouanet (1982), surgen reflexiones sobre la necesidad de un nuevo perfil de burócrata en un contexto de globalización económica y de reforma del Estado brasileño. La redemocratización y, por lo tanto, la entrada de nuevos actores en el proceso de toma de decisiones demostraron la necesidad de profesionalizar la burocracia superior, para generación de valor en los servicios públicos. El presente trabajo tiene como objetivo presentar una descripción de la trayectoria de la carrera de gestor gubernamental en el Estado brasileño de Mato Grosso, que es una de las más antiguas del país - todavía no hay trabajos publicados en la literatura sobre el contenido aquí presentado. Metodológicamente, la investigación, de carácter descriptivo, se apoyó en la recopilación de datos en marcos teóricos y legales, para en seguida ser hecho un análisis de los datos recogidos. Se concluyó que la carrera de gestor gubernamental de Mato Grosso tiende a la consolidación, como lo demuestra el número de servidores ocupantes del cargo, y su reconocimiento, para la aplicación de las políticas públicas del Estado de Mato Grosso.

Palabras clave: reforma administrativa, alta administración pública, carrera pública, capacitación profesional, administración regional, estudio de caso

\section{The construction of a bureaucratic elite: the case of government managers in Mato Grosso}

Since the Rouanet Report in Brazil (1982), there have been a lot of studies on the necessity of a new bureaucrat profile in a context of economic globalization and reform of the Brazilian state. The return to democracy and hence the entry of new participants in the decision-making process have demonstrated the necessity of professionalizing higher bureaucracy in Brazil, in order to create public service value. This study aims to present a description of the government management career development in the state of Mato Grosso, Brazil - which is one of the oldest careers in Brazil and there is still no published work on the content here presented. The type of methodology used in the research was descriptive and based on data collection in theoretical and legal frameworks. After that, an analysis of the collected data was made. We concluded that the current government management career in Mato Grosso tends to be consolidated, as demonstrated by the number of career members and the career role and recognition, for implementation of public policies in the State of Mato Grosso.

Keywords: administrative reform, top-level public administration, public career, professional training, regional administration, case study 


\section{Introdução}

Para realizar a análise, este artigo baseou-se em três fontes fundamentais. Primeiro, analisam-se os dispositivos legais que tratam da carreira de gestores governamentais de Mato Grosso. Esses documentos são constituidores de planos e políticas para atuação desses profissionais. Para auxiliar no estudo, foram feitas entrevistas com membros que vivenciaram a trajetória da carreira ao longo do período que vai de 2001 a 2014. Por fim, o estudo utiliza portarias, decretos e outros instrumentos regulamentadores da administração pública.

$\mathrm{O}$ artigo reflete avanços na consolidação da carreira de gestores governamentais de Mato Grosso, num contexto de reforma incompleta do Estado brasileiro e de Mato Grosso. As reflexões sobre a criação e percurso da carreira de Gestor Governamental em Mato Grosso, que teve sua criação concebida pelo nível estratégico e foi implementada pela média burocracia da área sistêmica, caracterizaram o perfil de operadores e não reformadores, como se pensava na concepção inicial da carreira.

Servidores generalistas, efetivos e capacitados a formular, implementar e avaliar políticas públicas, inseridos numa estrutura de Estado com fortes características patrimonialistas, enfrentaram e enfrentam fortes resistências ao longo de uma trajetória de desafios, entraves, retrocessos e avanços.

A dura trajetória proporcionou experiências suficientes para que esse grupo de servidores pudesse iniciar a construção de uma identidade e auxiliar o governo em diversos campos do núcleo estratégico, no ciclo das políticas públicas ou nos macroprocessos de gestão governamental.

\section{Reforma do Estado e profissionalização da gestão pública}

O objeto de reforma do Estado ganhou força a partir da década de 1980, quando as ideias liberais direcionaram as propostas de reforma do Estado nos Estados Unidos e na Inglaterra num contexto de globalização das economias mundiais. A experiência brasileira começa a ganhar contornos quando assume o primeiro presidente eleito diretamente pela população, após vinte e cinco anos sem eleições diretas, o Presidente Fernando Collor de Mello.

Após o governo do Presidente Fernando Collor de Mello, o Brasil assumiu uma direção efetiva de reforma do Estado a partir da instituição do Plano Diretor da Reforma do Aparelho do Estado (PDRAE), documento aprovado no primeiro mandato do Governo de Fernando Henrique Cardoso.

Assim, pode-se afirmar que a reforma do Estado brasileiro atravessou dois processos: na década de 1980, quando foi oriunda do esgotamento do regime ditatorial, e nos anos 1990, resultante de um processo de internacionalização econômica e das diretrizes liberalizantes da economia propostas pelo Consenso de Washington. 
A mudança do regime dos militares para o democrático, deu-se no Brasil por meio de um grande pacto político, que de maneira informal demonstrava que o Estado deveria reestabelecer os direitos políticos e prover a sociedade de um aparato estatal que reduzisse as históricas desigualdades sociais e econômicas. Mas esse acordo político, no que se refere à redução das desigualdades sociais, não foi cumprido por carência de recursos para atender plenamente a todas as demandas sociais incluídas na Constituição brasileira de 1988, como bem atesta Bresser-Pereira:

Para tornar o Estado brasileiro um Estado social, era preciso aumentar substancialmente a despesa pública social. E isto foi feito. Em 1985, ela representava cerca de $11 \%$ da renda nacional, hoje representa $23 \%$. Quando, no Ministério da Administração Federal e Reforma do Estado, eu dei início a Reforma Gerencial do Estado de 1995, eu estava respondendo a essa nova realidade que era o Estado social brasileiro (MоTA et al., 2011).

A reforma do Estado brasileiro foi induzida pela dupla ingerência de dois agentes financeiros internacionais: Banco Mundial e o Fundo Monetário Internacional (FMI). Segundo essas instituições, para o crescimento econômico ser estável num cenário de maior competitividade dos mercados internacionais, faz-se necessário que os estados sejam competitivos por meio do equilíbrio orçamentário e estabilidade monetária, com capacidade de propiciar o cálculo econômico para efeito das transações comerciais cada vez mais globalizadas. Como lembra Paulo Nogueira Batista Jr., "as nações hegemônicas operam de forma a beneficiar aqueles que se dispõem a cooperar com os seus projetos de poder" (BATISTA JR., 2007).

Na década de 1990, o Governo Fernando Henrique Cardoso adotou o discurso de que a crise do Estado era fato consumado a partir do esgotamento do modelo desenvolvimentista e inseriu na agenda governamental a necessidade de uma reforma de Estado. A reestruturação do Estado foi colocada como ponto crucial para que o Brasil pudesse retomar o caminho do crescimento econômico e a estratégia adotada para superar as resistências políticas foi adotar um viés estritamente econômico, associada à crise fiscal e à perda da capacidade de investimento público. Assim, vimos uma crise fiscal traduzida em uma crise gerencial e, dessa forma, a reforma do Estado foi convertida em uma discussão técnica e administrativa sem conotação política e, consequentemente, sem a participação da sociedade civil organizada.

\section{Reforma Técnica do Estado: um corpo funcional técnico para consolidação}

A profissionalização do núcleo estratégico do governo é considerada por Abrucio (2007) como um dos eixos estratégicos para a renovação da agenda reformista da gestão pública. O autor destaca a necessidade de uma boa alocação dos cargos de provimento em comissão, de maneira que haja uma delimitação clara entre a arena 
política e administrativa: "uma parte importante desses cargos deve ser preenchida necessariamente pela burocracia estatal, sendo que os agentes políticos devem escolher, na maioria das vezes, os funcionários de carreira que devem ocupar tais postos" (ABRUCIO, 2007). O autor também reconhece que uma parte desses cargos deveria trazer pessoas de fora, uma espécie de recrutamento externo, com "profissionais do mercado e da academia para oxigenar a administração pública e incorporar novas técnicas transparentes e mesmo competitivas" (ABRUCIO, 2007).

Assim embasado no relatório do embaixador Rouanet de 1982, no final da década de 1980, criou-se a carreira de Especialista em Políticas Públicas e Gestão Governamental (EPPGG), que havia diagnosticado que as descontinuidades tanto na execução de reformas administrativas quanto na implementação de políticas públicas eram geradas pela baixa capacitação dos quadros da administração pública e pela ausência de critérios objetivos para o acesso às funções estratégicas da máquina administrativa do Estado. O estudo recomendou a criação de uma carreira com perfil adequado e uma instituição de ensino voltada para a formação continuada do núcleo estratégico da burocracia do Estado brasileiro. BresserPereira consolidou essa ideia, afirmando que "uma estratégia essencial é reforçar o núcleo estratégico, ocupando-o com servidores públicos altamente competentes, bem treinados e bem pagos." (BRESSER-PEREIRA, 2007).

\section{Embriogênese da carreira de EPPGG}

Em 1982, o embaixador Sergio Paulo Rouanet foi designado pelo Ministro de Estado das Relações Exteriores para atuar de maneira cooperativa com o Departamento Administrativo do Serviço Público (DASP) na busca de alternativas que pudessem levar a proposta de formulação de diretrizes de uma Escola Superior de Administração Pública no Brasil. José Carlos Freire, o então Diretor-Geral do DASP, e seus assessores pensavam em criar uma escola aos moldes da Escola Nacional de Administração (ENA), da França, e, em menor densidade, aos de outras instituições estrangeiras, como a Academia Federal de Administração Pública da República Federal da Alemanha.

Para auxiliar o DASP, Rouanet realizou, no mesmo ano, um trabalho de pesquisa no Brasil e no Exterior que culminou em um relatório intitulado "Criação no Brasil de uma escola superior de administração pública". O relatório foi dividido em três partes: investigação de escolas oficiais existentes no Brasil e suas interações com o Estado; investigação de modelos estrangeiros, principalmente o francês, e recomendações à luz das duas partes anteriores. Nessa terceira parte, o Relatório Rouanet recomendou a implantação no Brasil de um modelo semelhante ao da França e assim foi concebido: a criação de uma escola voltada à profissionalização dos agentes públicos aprovados em concurso público, para compor os cargos estratégicos da administração pública federal. 
Do Relatório Rouanet, durante o Governo do Presidente Sarney (1985-1990), surgiu a Escola Nacional de Administração Pública (Enap), instituída pelo Decreto no 93.277 de 19 de setembro de 1986, e a carreira de Especialista em Políticas Públicas e Gestão Governamental (EPPGG), pela Lei no 7.834 de 12 de agosto de 1989. Nessa lei, foi atribuída ao EPPGG a atribuição de "execução de atividades de formulação, implementação e avaliação de políticas públicas, bem assim de direção e assessoramento em escalões superiores da administração direta e autárquica" (LEI no 7.834, 1989). O Decreto no 5.176, de 10 de agosto de 2004, regulamentou a carreira atribuindo-lhe:

O exercício de atividades de gestão governamental nos aspectos técnicos relativos à formulação, implementação e avaliação de políticas públicas, bem assim de direção e assessoramento em escalões superiores da administração pública federal direta, autárquica e fundacional, em graus variados de complexidade, responsabilidade e autonomia (DECRETO № 5.176, 2004).

Essa carreira é integrada por indivíduos aprovados em concurso público e curso de formação na Enap. Entretanto, não foram garantidos meios para uma clara inserção na alta direção do Estado, como acontece na França e Inglaterra.

Durante a Presidência de Fernando Collor de Mello (1990-1992), a carreira de EPPGG careceu de patrocínio político, sendo extinta e seus cargos transformados em Analista de Planejamento e Orçamento; mas ao final do Governo Collor, a carreira foi reestabelecida por meio da Lei no 8.460, de 17 de setembro de 1992.

De 1994 a 1998, com o advento do Plano Diretor da Reforma do Aparelho do Estado em 1995, a Enap passou a disseminar as estratégias da administração pública gerencial aos servidores públicos federais; como consequência, houve a reativação dos concursos para as carreiras de EPPGG e de Analista de Planejamento e Orçamento, com ênfase na nova administração pública. A partir da retomada dos concursos para EPPGG em 1995, exigiu-se dos pretensos candidatos conhecimento em nível de pós-graduação e submissão a um curso de formação específico, promovido pela Enap.

Ao longo dos dois mandatos presidenciais (1995-2002) do então Presidente Fernando Henrique Cardoso, formaram-se seis turmas de EPPGG. Em 1998, antes do fim do primeiro mandato presidencial do Presidente Fernando Henrique Cardoso, promoveram-se alterações nas atribuições da carreira, numa tentativa de aproximá-la de outras carreiras, para fins de viabilização do ciclo de gestão do Governo Federal.

No período condizente aos dois mandatos do Presidente Luiz Inácio Lula da Silva (2003-2010), a carreira dos EPPGGs obteve um reajuste nominal no subsídio inicial 
da carreira de $545,48 \%$, para uma inflação no período de $46,31 \%$. No Governo da Presidente Dilma Rousseff (2011-2014), houve alguns retrocessos na relação entre a Associação dos EPPGGs e a Secretaria de Gestão Pública do Ministério do Planejamento, Orçamento e Gestão causados por desacordos nos processos de mobilidade, capacitação e concurso de seleção de novos membros.

A trajetória da carreira federal de gestores governamentais reflete os avanços e retrocessos da carreira estadual de Mato Grosso, explicados por meio do isomorfismo: organizações que atuam num mesmo campo organizacional tendem a dirigir que tenham comportamento similar em resposta a pressões externas e internas. Essas pressões conduzem ao isomorfismo, que "constitui um processo de restrição que força uma unidade em uma população a se assemelhar a outras unidades que enfrentam o mesmo conjunto de condições ambientais" (HAWLEY, 1968, apud DIMAGGIO; POWELL, 2005).

\section{Criação da carreira de Gestor Governamental em Mato Grosso: Governo Dante de Oliveira-Rogério Salles (2001-2002)}

A carreira de Especialista em Políticas Públicas e Gestão Governamental da União serviu de referencial e modelo para a criação, pelas autoridades políticas, da carreira estadual de Gestor Governamental de Mato Grosso e são apresentadas como resposta a uma necessidade de reforma do Estado: apresentando o perfil generalista dos profissionais, foco em resultados e na eficiência das políticas públicas. Em função do caráter estratégico que a profissionalização da gestão pública assume num contexto de reforma de Estado inconclusa, fazem-se necessários estudos que qualifiquem e fundamentem ações no sentido de modernizar a máquina pública dos estados federados, em especial o Mato Grosso, objeto da presente pesquisa.

Antes de descrever a gênese da carreira de Gestor Governamental em Mato Grosso, é preciso abordar a política de gestão do Governo Dante de Oliveira (19952002) que a idealizou e começou a implantá-la.

Como descreve Araújo (2005), a reforma empreendida nos dois mandatos do governador Dante de Oliveira foi pautada nos seguintes eixos:

1. o Programa de Reforma do Estado, criado pelo Decreto no 752 de 22/01/1996, que resultou no Conselho Diretor do Programa de Reforma do Estado (CDPRE), contando com aporte técnico-financeiro do Banco Mundial, num empréstimo garantido pela União;

2. a adesão ao Programa Nacional de Apoio à Administração Fiscal para os Estados Brasileiros (Pnafe), financiado pelo Banco Interamericano de Desenvolvimento (BID); 
3. renegociação da dívida estadual cujos marcos foram a Lei Estadual no 6.871, de 28/04/1997, e a Lei Federal no 9.496, de 11/09/1997, que consolidou o acordo com todos os Estados.

Como resultado da interação dos dois programas (Pnafe e CDPRE) baseados em financiamentos externos com prazos determinados, ocorreu em abril de 2000 a formação de uma equipe para apresentar um diagnóstico do Estado. Seu conteúdo era a situação gerencial do momento e a proposição de um novo modelo de gestão para todo o aparelho. Assim, surge em abril de 2001 o Programa de Modernização da Gestão (PMG), cujos princípios, pressupostos e a própria estrutura foram influenciados pela Gestão da Qualidade Total, muito difundida no Brasil na década de 1990, em especial no setor industrial e de serviços.

A equipe técnica engajada nesses programas começou a se preocupar com a sua continuidade, num momento em que o objetivo maior do ajuste fiscal já fora alcançado e se caminhava para a fase final daquele mandato. Os técnicos do BID também faziam questão de apontar em seus relatórios e reuniões de monitoramento a importância de profissionalizar a gestão financeira.

Assim, sob grande influência dos técnicos do BID e da experiência dos Especialistas em Políticas Públicas e Gestão Governamental (EPPGG) em âmbito federal, optouse pela criação de uma nova carreira.

Havia vários projetos para a criação dessa carreira em disputa no interior do grupo técnico e também no secretariado da área sistêmica, sendo seus principais:

1. Construir uma carreira moldada nos EPPGGs do Governo Federal.

2. Substituir, por gestores governamentais, os técnicos da Companhia de Desenvolvimento (Codemat) e da Companhia de Mineração do Estado de Mato Grosso (Metamat) lotados na Secretaria de Planejamento e Coordenação Geral (Seplan), bem como os técnicos lotados na Secretaria de Fazenda (Sefaz) cedidos pelo Centro de Processamento de Dados (Cepromat).

3. Profissionalizar a gestão financeira, conforme sugestão dos técnicos do BID no Pnafe.

4. Formar multiplicadores do modelo de gestão ora em vigor (inspirado nas ferramentas da Gestão pela Qualidade Total).

5. Possuir apenas um corpo técnico de elite, selecionado por um concurso mais rigoroso e preparado pelo curso de formação.

Diante dessas discussões, a lei da carreira foi sancionada em 13 de dezembro de 2000, com o número 7.350. Ela criou 110 vagas para lotação distribuídas em três secretarias, sendo 60 na Secretaria de Planejamento e Coordenação-Geral (Seplan), 30 na Secretaria de Fazenda (Sefaz) e 20 na Secretaria de Administração (SAD). 
As competências definidas em lei foram no sentido de executar as atividades de formulação, implantação e avaliação de políticas públicas e assessoramento técnico, e tinham como objetivo que os servidores fossem profissionais que percorressem tudo aquilo que se conceitua como ciclo de políticas públicas.

A Lei no 7.350/2000 definiu também atribuições diferentes para as três secretarias. Elas tratavam dos sistemas administrativos de competência de cada uma delas. Predominava uma visão com forte influência do já mencionado Pnafe, na qual os gestores governamentais seriam agentes de modernização da gestão baseados nas secretarias da área-meio e as inovações se difundiriam pela administração pública estadual por meio dos sistemas liderados por elas. Além disso, pesava muito a concepção de que esses servidores seriam substitutos da antiga geração de técnicos na área administrativa, providos em sua maioria pelas entidades da administração indireta e as carreiras fiscais.

Essa ambiguidade, de entender os gestores governamentais como agentes de modernização ou substitutos da antiga geração de técnicos na área administrativa, marcou todo o processo e acabou sendo um dos principais fatores que dificultaram a falta de consolidação da carreira. Qual seria o papel dos gestores? Operadores ou reformadores? No segundo caso, qual seria o modelo de reforma do Estado?

Na lei de criação da carreira, alguns mecanismos foram adotados no sentido de selecionar e formar servidores para constituir uma elite burocrática no governo. O subsídio inicial foi definido em $\mathrm{R} \$ 2.500$ e significava, na época, um valor que equivaleria a $72 \%$ do subsídio dos EPPGGs do Governo Federal, e se aproximava do subsídio recebido por outras carreiras de gestão dos governos estaduais e também das principais carreiras do governo do Estado de Mato Grosso. Esses dados serão discutidos a seguir (Gráfico 1 e Tabela 1).

As classes que formavam o plano da carreira foram distribuídas em quatro níveis conforme as letras A, B, C e D. Cada classe representava uma titulação (graduado, especialista, mestre e doutor) e era outra maneira de atrair candidatos com elevada qualificação educacional. A lei ainda previa que o enquadramento inicial se daria na classe correspondente à titulação possuída. Outros dispositivos trazidos pela lei referiam-se ao concurso, que seria dividido em duas fases (objetiva e discursiva), aliadas a um curso de formação eliminatório (a exemplo dos EPPGGs federais) com nota de corte mínima de $70 \%$ em todas as etapas, de modo a selecionar candidatos com elevado desempenho.

Foram realizados dois concursos no ano de 2001. O primeiro com edital publicado em março de 2001, com oferta de 110 vagas de nomeação imediata e 40 vagas que formariam um cadastro-reserva; logo, seriam selecionados os 150 melhores classificados nas provas objetivas e discursivas para participar da segunda etapa 
do concurso, o curso de formação. O curso de formação era mais um mecanismo raro em concursos e que buscava induzir mais um momento de competição entre os candidatos e recrutamento daqueles que obtivessem maior pontuação. $O$ rigor nessa seleção acabou sendo, talvez, muito elevado pela nota de corte alta. No primeiro concurso da carreira, apenas 41 candidatos atingiram $70 \%$ nas duas provas (objetiva e dissertativa) e ficaram habilitados a fazer o curso de formação. Desses, apenas 37 se matricularam no curso de formação, 36 foram nomeados e 34 tomaram posse.

Em julho de 2001, foi publicado um segundo edital para novamente tentar alcançar o que se pretendia: 110 cargos para nomeação imediata e 40 candidatos classificados para formação de um cadastro-reserva. Assim, no segundo concurso, editado com o mesmo rigor do primeiro edital (nota de corte de no mínimo 70\%), apenas 61 candidatos passaram por todas as etapas e foram nomeados, deixando a carreira com 15 cargos vagos e impossibilitada de formar um cadastro-reserva.

O cenário de inserção inicial para a carreira revelou todas as tensões presentes na concepção e implementação do projeto. O primeiro aspecto foi o período, já que as nomeações aconteceram no final do Governo Dante de Oliveira (19952002). O caso da segunda turma foi ainda mais evidente, uma vez que a nomeação aconteceu em março de 2002 e, no início de abril, o governador Dante de Oliveira renunciou ao mandato para concorrer a senador, transmitindo o cargo para José Rogério Salles. Com a troca de comando, ocorreram as tradicionais mudanças no secretariado por conta do novo governador e do ano eleitoral, inclusive nas secretarias de administração sistêmica em que estavam lotados os gestores governamentais. Embora os secretários já fizessem parte do governo anterior, as alterações trouxeram as conhecidas descontinuidades. Assim, o governador que criou a carreira não teve a oportunidade de implantá-la, o que prejudicou o projeto.

No ambiente político mais amplo, a eleição de 2002 foi uma das mais polarizadas da história de Mato Grosso, considerada por Araújo (2012) como uma eleição de fim de ciclo, marcando a transferência de comando da elite política formada no pós-divisão (de Mato Grosso e Mato Grosso do Sul) para os novos atores surgidos nas décadas de 1980 e 1990. Com a eleição de Blairo Maggi (PPS), a carreira conheceu o terceiro governador nos seus primeiros 18 meses de vida. Maggi foi eleito numa coalizão de oposição em relação ao governo anterior, cujo candidato à sucessão era o então senador Antero Paes de Barros (PSDB). Depois de sua posse, a troca do secretariado foi praticamente completa, criando um cenário de grande incerteza. 


\section{Preparação dos membros da carreira de Gestor Governamental: Governo Blairo Maggi (2003-2010)}

Durante o Governo Blairo Maggi (2003-2010), continuou a forte tendência em favor da Secretaria de Fazenda, só que sem a ênfase no modelo de gestão por resultados do governo anterior. Isso retirou um dos projetos de inserção pensado para a carreira em seu momento fundador, como multiplicadores das ferramentas da qualidade total. Prosseguiu a tendência de esvaziamento da agenda tradicional de planejamento e o pêndulo caminhou para a gestão, em virtude do caráter claro de processos de suporte às políticas finalísticas e seus produtos apresentados por essa última.

Nesse contexto, o eixo da gestão deslocou-se da Secretaria de Fazenda/Secretaria de Planejamento para a Secretaria de Administração/Auditoria Geral/Centro de Processamento de Dados, com a ida do Programa Nacional de Apoio à Modernização da Gestão e do Planejamento dos Estados Brasileiros e do Distrito Federal (PNAGE) para a Secretaria de Administração, a ascensão da função controle (auditoria) e o desmonte das superintendências de gestão e tecnologia da informação na Secretaria de Planejamento.

Os traços mais fortes desse governo na área de gestão foram a ênfase nos sistemas corporativos (Sigplan, Fiplan, Siag, Seap, Sigpat, SIGP), a valorização do controle e a centralização decisória. No primeiro mandato, houve a criação de várias entidades da administração indireta, como não se via desde a década de 1970, e a implantação dos núcleos sistêmicos, que tinham por objetivo agrupar as áreas de administração sistêmica em um conjunto de órgãos, numa unidade de prestação de serviços especializados, de modo a liberá-los para as suas atividades finalísticas ou de execução programática.

Toda essa situação contaminou o ambiente político interno da carreira e sua relação com o governo. Os dois primeiros anos foram marcados por muitas tensões e debates sobre as competências da carreira, seu modelo de governança, perfil dos seus ocupantes e da agenda de gestão do governo que terminava.

Os gestores da Secretaria de Planejamento apresentaram propostas no sentido de federalizar as ferramentas de gestão e planejamento, articulando a inserção da carreira à implantação do modelo de gestão por programas adotado pelo Ministério de Planejamento, Orçamento e Gestão (MPOG) no segundo Governo Fernando Henrique Cardoso (1999-2002). Havia também um forte posicionamento em favor da gestão de políticas públicas, visando avançar sobre o conteúdo das secretarias finalísticas e superar o papel restrito de instrumentação até então exercido. Em paralelo, foi aberta pela Secretaria de Administração a possibilidade de aumento salarial e outras alterações na lei da carreira. 
Para que essas discussões sobre os rumos da carreira fossem organizadas, houve a criação de grupos de trabalho, primeiro na Secretaria de Planejamento e depois envolvendo os gestores das demais secretarias. Em 2003, a discussão se polarizou em duas grandes posições, com a primeira advogando mudanças no marco regulatório da carreira e a segunda defendendo prioridade para negociação salarial. As principais teses defendidas para mudança na legislação e atuação da carreira eram:

1. lotação centralizada da carreira no Gabinete do Governador, de modo a facilitar a sua gestão;

2. instalação de gestão colegiada para a carreira, por meio de um conselho gestor envolvendo as três secretarias de administração sistêmica, como uma secretaria executiva;

3. criação de uma unidade de coordenação para a carreira;

4. ênfase em atividades de capacitação, estudos e pesquisas;

5. criação de duas áreas de atuação, gestão de políticas públicas (área finalística) e sistemas e processos de gestão (área sistêmica).

Todas elas acabaram sendo codificadas pela Lei $n=8.032$, de 17/12/2003, que também reajustou o subsídio, concedendo um aumento de $40 \%$ para a classe $A$, cerca de $60 \%$ para a B, $72 \%$ para a $C$ e $85 \%$ para a D. Foi um aumento considerável, em particular se considerarmos que os índices acumulados de inflação para o período ficaram entre 33\% (IPCA) e 51\% (IGP-DI).

O reajuste gerou, entretanto, consideráveis problemas políticos para a carreira, uma vez que os secretários de Estado que articularam a sua aprovação ou saíram do Poder Executivo (Carlos Brito) ou foram para secretarias finalísticas (Marcos Machado), gerando uma nova orfandade para a carreira em termos de patrocinador político.

A transferência para o Gabinete do Governador revelou-se também um complicador técnico e político, já que ele não existia como unidade administrativa. Diante disso, a Casa Civil acabou sendo o órgão de destino.

No período 2003-2009, a carreira assistiu à evasão de seus servidores sem a possibilidade de reposição imediata, pois os dois concursos realizados para a carreira em 2001 tiveram seus prazos de vigência finalizados, sem deixar classificados para novas nomeações. Em 2004, foi criada a Associação dos Gestores Governamentais do Estado de Mato Grosso (AGGEMT) e, a partir de então, houve várias tentativas de articulação e definição de uma identidade à carreira, como, por exemplo, uma série de debates conduzidos pela Secretaria Executiva do Conselho Gestor, visando à elaboração de um planejamento estratégico em 2005. Na transição do primeiro para o segundo mandato de Blairo Maggi, foi apresentado ao Chefe da Casa Civil 
e ao governador um conjunto de propostas na área de gestão, acompanhado das realizações da carreira nesse período inicial.

O que marcou esse momento foi a dificuldade para realização de um novo concurso e para obtenção de reajustes salariais diferenciados, já que o governo estabeleceu política salarial de revisão automática, a partir de 2005 , por meio da Lei Estadual no 8.278/04.

Na mesma época, foram realizados concursos para a carreira de Profissional da Área Instrumental de Governo criada pela Lei no 7.461, de 13/07/2001. Essa carreira surgiu oriunda da transformação de cargos avulsos de nível fundamental, médio e superior existentes nas secretarias de administração sistêmica em uma carreira horizontal, que pudesse desempenhar suas funções em tais secretarias e também na área-meio das finalísticas.

Com a realização de dois concursos para a área instrumental do governo (em 2004 e 2006) e a ampliação do número de vagas, essa carreira passou a ocupar o espaço de nova burocracia da área-meio pretendida por muitos para a carreira de gestores, frustrando uma das estratégias de inserção concebidas no início. Além disso, muitos empregados públicos de empresas estatais, em exercício nas secretarias de administração sistêmica, impetraram ações no Poder Judiciário para buscar a reintegração como servidores estatutários e obtiveram êxito. Isso acabou alongando a presença deles na área de gestão, que se considerava rápida no momento de criação da carreira de gestores.

A outra estratégia era de transformar os gestores em profissionais especializados na gestão financeira do estado, uma espécie de grupo TAF da despesa ${ }^{1}$, no sentido de melhorarem a qualidade do gasto. Essa também se revelou frustrada com o crescimento das carreiras de controle, com destaque para a carreira de auditores do estado. Nesse período, os auditores conseguiram a aprovação de duas leis para reajuste de salários, conquistaram a sede própria, houve a realização de dois concursos e, como consequência da valorização e fortalecimento institucional da carreira, foi nomeado um servidor da carreira para ocupar o cargo de AuditorGeral. Essa estrutura foi consequência do fortalecimento do controle externo. Os dirigentes políticos entendiam que se faziam necessários bons servidores para organizar os aspectos formais das contas públicas para o TCE, sem interferência no conteúdo das políticas.

Dessa forma, com a mudança de eixo na política de gestão pública, o auditor passou a ser o grupo TAF da despesa que se propunha para o gestor. A carreira de

\footnotetext{
${ }^{1}$ Grupo TAF é a simbologia utilizada para definir a carreira formada por cargos na área fiscal, significando tributação, arrecadação e fiscalização.
} 
auditor passou a ter um peso institucional maior, além de ter uma prática profissional mais bem definida, com instrumentos de trabalho consolidados e estruturados.

Houve ainda aprovação das Leis no 8.873/08 e 9.317/10, que não alteraram o modelo de gestão da carreira, apenas mudaram critérios de progressão entre classes e níveis. Pela elevada amplitude deixada pela tabela salarial aprovada em 2003 (64\%) e o fato de a maioria dos servidores da carreira estar já nas classes C e D, foi privilegiada a política de flexibilização dos critérios de progressão interclasses, de modo a obter reajustes salariais indiretos. O efeito positivo disso foi a retenção de parte dos servidores da carreira, já que sem essa valorização salarial a migração para outros concursos poderia ter sido maior.

Dos quatro projetos disputados no início da implantação da carreira, restaram dois: uma carreira nos moldes dos EPPGGs federal e a transformação da carreira em um corpo técnico de elite. Nesse período, acabou predominando o segundo. O subsídio da carreira recebeu apenas os reajustes lineares concedidos pelo Poder Executivo, ficando o subsídio defasado em relação ao salário mínimo (Gráfico 1) e às outras carreiras similares, como os auditores estaduais e os EPPGGs do Governo Federal (Tabela 1). Uma estratégia de diferenciação adotada por parte da carreira foi a capacitação em nível de pós-graduação. Um grupo de 15 gestores governamentais optou por cursar mestrados e outras duas gestoras buscaram doutorados em suas respectivas áreas, o que levou a carreira a apresentar o mais alto percentual de titulação da administração direta, ficando abaixo apenas da Universidade do Estado (Unemat). Muitos optaram também pela capacitação em serviço, aprofundando-se nos seus respectivos projetos.

\section{Gráfico 1: Evolução do subsídio inicial do Gestor Governamental em MT, em relação ao salário mínimo (2001-2014)}

Subsídio/Salário Mínimo

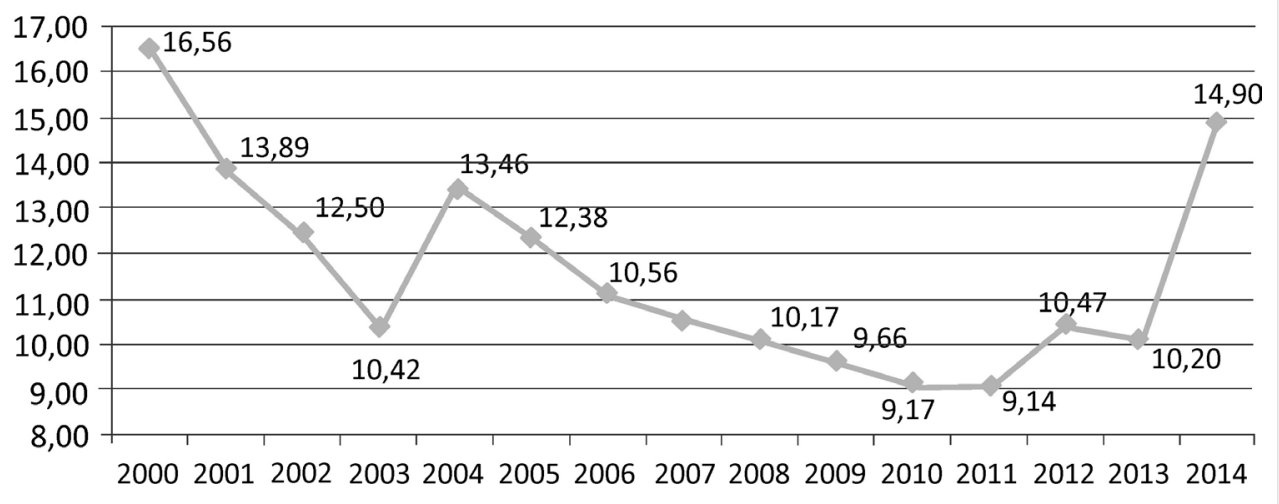

Fonte: Elaboração própria. 
Tabela 1: Evolução do subsídio inicial dos gestores governamentais em relação às carreiras próximas (2001-2014)

\begin{tabular}{l|l|l|l|l|l|l|l}
\hline Ano & $\begin{array}{c}\text { Gestor } \\
\text { governa- } \\
\text { mental }\end{array}$ & Auditor & $\begin{array}{c}\text { EPPGG } \\
\text { federal }\end{array}$ & $\begin{array}{c}\text { TAIG } \\
\text { (Analista } \\
\text { administra- } \\
\text { tivo) }\end{array}$ & $\begin{array}{c}\text { Gestor/ } \\
\text { Auditor }\end{array}$ & $\begin{array}{c}\text { Gestor/ } \\
\text { EPPGG }\end{array}$ & $\begin{array}{c}\text { Gestor/ } \\
\text { TAIG }\end{array}$ \\
\hline 2001 & $2.500,00$ & $2.500,00$ & $3.433,75$ & $1.600,00$ & $100 \%$ & $73 \%$ & $156 \%$ \\
\hline 2005 & $3.715,00$ & $3.330,00$ & $6.076,45$ & $1.760,00$ & $112 \%$ & $61 \%$ & $211 \%$ \\
\hline 2009 & $4.492,17$ & $6.000,00$ & $10.905,76$ & $2.185,00$ & $75 \%$ & $41 \%$ & $206 \%$ \\
\hline 2013 & $6.915,00$ & $7.950,41$ & $13.608,81$ & $3.225,86$ & $87 \%$ & $51 \%$ & $214 \%$ \\
\hline 2014 & $10.784,00 *$ & $12.800,00$ & $14.275,64$ & $3.868,19$ & $84 \%$ & $76 \%$ & $279 \%$ \\
\hline Variação & $331 \%$ & $412 \%$ & $316 \%$ & $142 \%$ & & & \\
\hline
\end{tabular}

* A partir de outubro/2014

Fonte: Elaboração própria.

\section{Reestruturação da carreira de Gestor Governamental: Governo Silval Barbosa (2010-2014)}

Em 2009, foram incluídas 50 vagas para provimento de cargos de Gestor Governamental no grande concurso realizado pelo estado, já que naquele momento havia 55 cargos disponíveis. A carreira teve a oportunidade de participar da comissão que elaborou o edital para o concurso, aproximando-o bastante daquele praticado pelos EPPGGs do Governo Federal em 2008.

Nesse período, a carreira demonstrou flexibilidade e deu grandes contribuições em processos críticos na área de gestão. Vários tiveram a oportunidade de assumir posições importantes na administração pública, na transição entre os governos, como secretários adjuntos, assessores e superintendentes. Dessa maneira, os gestores governamentais se posicionaram como uma carreira estratégica, ocupando na sua maioria cargos e funções ligadas aos níveis mais elevados da administração pública. Foi mantida também a média histórica de ocupação de cargos comissionados (entre $35 \%$ a $40 \%$ ), além do exercício de funções importantes, com cerca de $70 \%$ respondendo diretamente a secretário de Estado ou secretário adjunto em atividades também de assessoria. Basta dizer que, entre os anos de 2008 e 2012, a carreira teve oito de seus integrantes exercendo a função de secretário adjunto em seis secretarias estaduais diferentes.

Além disso, um grande número de servidores da carreira mudou de lugar desde o início do Governo Silval Barbosa e a mobilidade tornou-se um dos eixos da nova política de gestão implementada, como se verifica na Tabela 2. 
Tabela 2: Distribuição dos gestores governamentais por órgãos e entidades estaduais e entre as áreas sistêmicas e finalísticas no período de maio/2002 a maio/2014

\begin{tabular}{|c|c|c|c|c|}
\hline \multirow{2}{*}{ Órgão/Entidade } & \multicolumn{4}{|c|}{ Mês de apuração do dado } \\
\hline & maio/02 & abr./10 & set./12 & maio/14 \\
\hline Auditoria-Geral & - & - & - & 1 \\
\hline $\begin{array}{l}\text { Agência de Desenvolvimento } \\
\text { Metropolitano do Vale do Rio Cuiabá }\end{array}$ & - & - & - & 2 \\
\hline Casa Civil & - & 6 & 3 & 2 \\
\hline Defensoria Pública & - & - & - & 1 \\
\hline Ministério Público & - & - & - & 1 \\
\hline MT Participações e Projetos & - & - & 1 & 3 \\
\hline MT Saúde & - & - & 1 & 1 \\
\hline Prefeitura de Cuiabá & - & - & 1 & 1 \\
\hline Secretaria de Administração & 16 & 15 & 8 & 15 \\
\hline Secretaria das Cidades & - & - & 2 & 5 \\
\hline Secretaria de Ciência e Tecnologia & - & - & 1 & 1 \\
\hline $\begin{array}{l}\text { Secretaria Extraordinária da Copa do } \\
\text { Mundo - Fifa } 2014\end{array}$ & - & - & 2 & 9 \\
\hline $\begin{array}{l}\text { Secretaria de Desenvolvimento do } \\
\text { Turismo }\end{array}$ & - & - & 1 & 3 \\
\hline Secretaria de Educação & - & 1 & 1 & 3 \\
\hline Secretaria de Fazenda & 30 & 7 & 2 & 2 \\
\hline $\begin{array}{l}\text { Secretaria de Justiça e Direitos } \\
\text { Humanos }\end{array}$ & - & - & 4 & 5 \\
\hline $\begin{array}{l}\text { Secretaria de Justiça e Segurança } \\
\text { Pública }\end{array}$ & - & 1 & - & 5 \\
\hline Secretaria de Meio Ambiente & - & - & - & 1 \\
\hline $\begin{array}{l}\text { Secretaria de Planejamento e } \\
\text { Coordenação-Geral }\end{array}$ & 46 & 18 & 17 & 41 \\
\hline Secretaria de Saúde & - & - & 2 & 3 \\
\hline $\begin{array}{l}\text { Secretaria de Transporte e } \\
\text { Pavimentação Urbana }\end{array}$ & - & - & - & 3 \\
\hline Universidade do Estado & - & - & - & 1 \\
\hline Departamento de Trânsito & - & 1 & - & - \\
\hline Secretaria de Cultura & - & 1 & - & - \\
\hline $\begin{array}{l}\text { Secretaria Extraordinária de Apoio às } \\
\text { Políticas Educacionais }\end{array}$ & - & 1 & - & - \\
\hline
\end{tabular}




\begin{tabular}{l|c|c|c|c}
\hline \multirow{2}{*}{ Órgão/Entidade } & \multicolumn{4}{|c}{ Mês de apuração do dado } \\
\cline { 2 - 5 } & maio/02 & abr./10 & set./12 & maio/14 \\
\hline $\begin{array}{l}\text { Secretaria de Trabalho e Assistência } \\
\text { Social }\end{array}$ & - & 1 & - & - \\
\hline $\begin{array}{l}\text { Secretaria de Logística Intermodal de } \\
\text { Transporte }\end{array}$ & - & - & 1 & - \\
\hline Vice-Governadoria & - & - & - & 1 \\
\hline Total Geral & $\mathbf{9 2}$ & $\mathbf{5 2}$ & $\mathbf{4 7}$ & $\mathbf{1 1 0}$ \\
\hline Área Sistêmica & 92 & 40 & 27 & 58 \\
\hline Área Finalística & 0 & 12 & 20 & 52 \\
\hline Área Sistêmica & $100,00 \%$ & $76,92 \%$ & $57,45 \%$ & $52,73 \%$ \\
\hline Área Finalística & $0,00 \%$ & $23,08 \%$ & $42,55 \%$ & $47,27 \%$ \\
\hline
\end{tabular}

Fonte: Elaboração própria.

No começo de 2011, a agenda da carreira estava bastante congestionada, em função das dificuldades dos anos anteriores. Os principais pontos da pauta eram:

1. melhoria na forma de inserção;

2. transferência da lotação para a Secretaria de Planejamento;

3. reajuste salarial;

4. conclusão do concurso.

Quanto ao primeiro item, foram retomadas as discussões sobre inserção dos gestores governamentais por ocasião de uma nova eleição para a associação e secretaria executiva do Conselho Gestor em setembro de 2010. Depois, foram realizadas 9 reuniões entre março e maio de 2011 com esse foco e visando preparar a carreira e as secretarias de administração sistêmica para recepção dos novos servidores egressos do concurso. Após contínuas negociações com a Casa Civil, ficou acertada a transferência da lotação dos gestores governamentais para a Secretaria de Planejamento. A Lei no 9.736, de maio de 2014, concedeu reajuste salarial diferenciado para a carreira pela primeira vez em mais de oito anos e legalizou essa mudança. Outra medida contida nessa lei foi a criação de um Comitê Consultivo como unidade de assessoramento à Secretaria de Planejamento nos assuntos referentes à gestão da carreira, inspirado pela experiência do Programa de Modernização da Gestão com os EPPGGs do Governo Federal.

Ao longo de 2012 e 2013, foram apresentadas propostas pela coordenação da carreira para melhorar o seu gerenciamento, garantindo o exercício dos gestores em estágio probatório fora do órgão de alocação inicial e uma forma de pactuação de resultados entre a Seplan e os órgãos/entidades de exercício dos servidores. 
Após discussões no âmbito do Comitê Consultivo e da AGGEMT, foram editadas as Portarias no 15 e no 31, disciplinando instrumentos de gestão como termo de cooperação, termo de cessão, plano de atuação, monitoria e outros.

Quanto ao concurso, foram tomadas as medidas necessárias para finalização e posterior nomeação. Ele foi homologado em março de 2011 e houve forte expectativa de uma breve nomeação; no entanto, em julho de 2011, o concurso foi suspenso por decisão judicial e assim permaneceu até maio de 2013. Ao longo de 2013 e 2014, foram nomeados 74 novos gestores governamentais. Dos nomeados, 62 entraram em exercício e foram distribuídos por 16 órgãos, em conformidade com a nova política de gestão da carreira que prioriza os processos gerenciais tanto na área sistêmica quanto finalística (Tabela 3).

Tabela 3: Distribuição dos gestores governamentais nomeados no Governo Silval Barbosa

\begin{tabular}{l|c}
\hline Órgão/Entidade & $\begin{array}{c}\text { Quantidade de Gestores } \\
\text { em atuação }\end{array}$ \\
\hline $\begin{array}{l}\text { Agência de Desenvolvimento Metropolitano do } \\
\text { Vale do Rio Cuiabá }\end{array}$ & 1 \\
\hline Defensoria Pública & 1 \\
\hline MT Participações e Projetos & 1 \\
\hline Secretaria de Administração & 9 \\
\hline Secretaria das Cidades & 5 \\
\hline Secretaria Extraordinária da Copa do Mundo - Fifa & 7 \\
2014 & 2 \\
\hline Secretaria de Desenvolvimento do Turismo & 2 \\
\hline Secretaria de Educação & 1 \\
\hline Secretaria de Fazenda & 2 \\
\hline Secretaria de Justiça e Direitos Humanos & 1 \\
\hline Secretaria de Meio Ambiente & 20 \\
\hline Secretaria de Planejamento e Coordenação-Geral & 1 \\
\hline Secretaria de Saúde & 4 \\
\hline Secretaria de Segurança Pública & 3 \\
\hline Secretaria de Transporte e Pavimentação Urbana & 1 \\
\hline Universidade do Estado & 1 \\
\hline Vice-Governadoria & 62 \\
\hline Total & \\
\hline
\end{tabular}

Fonte: Elaboração própria. 
A partir do diagnóstico das atuações dos membros que atuam fora do ambiente da lotação inicial (Secretaria de Planejamento), a coordenação da carreira de gestores governamentais de Mato Grosso, a fim de evitar o isolamento funcional e desvios funcionais que comprometeriam a identidade funcional da carreira, trabalhou num modelo de atuação em rede.

O modelo de atuação em rede consiste num mecanismo de troca de conhecimento entre os membros da carreira que atuam em áreas correlatas ou de interesse profissional. O objetivo precípuo é enriquecer o banco de conhecimento da carreira e, concomitante a isso, evitar o insulamento dos membros que atuam em outros ambientes institucionais, que não a Secretaria de Planejamento. As dificuldades enfrentadas pela carreira na ausência de um patrocínio político são superadas por meio de ações criativas, que permitem superar as estruturas arcaicas patrimoniais de poder.

\section{Considerações finais}

A Constituição Federal de 1988, ao atribuir claramente novas exigências à administração pública diante do processo de redemocratização, e a reforma do Estado brasileiro em 1995, com mudanças estruturais e conceituais, culminam na valorização de profissionais alocados estrategicamente para continuidade das políticas públicas em meio a um processo de transição política inerente ao regime democrático, como relata Aldino Graef (2010), que situa o episódio da criação da carreira dentro de um marco de análise mais ampla.

Graef afirma que a gênese do EPPGG federal deve ser buscada nos projetos de reforma institucional que antecederam e acompanharam a transição para a redemocratização. Para o autor, a carreira de EPPGG é o resultado de sucessivas formulações propostas por setores da tecnocracia, antes mesmo de iniciado o processo de transição, confluindo no desenho do gestor governamental como um perfil de servidor público destinado a renovar e fortalecer a burocracia.

A partir do levantamento explanado ao longo do artigo, foi possível perceber convergências entre as carreiras de gestores federais e de Mato Grosso, mas não uma fiel reprodução da carreira de âmbito federal no Estado de Mato Grosso. As características da carreira de Mato Grosso se adequam às características locais de cultura política e organizacional, preservando a amplitude das funções, com atribuições variadas e distintas, evidenciando a necessidade de profissionais que possam exercer diversos papéis dentro das organizações públicas com um perfil generalista.

A carreira de gestores governamentais de Mato Grosso, com a nomeação dos novos profissionais em meados de 2013, passou por uma renovação no quadro 
de pessoal e esse processo de ingresso dos novos servidores merece destaque por representar um marco de consolidação profissional. Com os novos profissionais, constatou-se que membros estão atuando espalhados por várias secretarias, com objetivo de fortalecer a efetividade da carreira. Esse mecanismo foi estabelecido como uma forma de atuação em rede, que torna a carreira capaz de colocar seus membros em contato com outros membros e com sua coordenação na secretaria de lotação inicial. Essa articulação de ação coletiva e produção de resultados apresentados são premissas adotadas para uma atuação em rede. Os objetivos específicos da rede de ação são informar os membros de assuntos de gestão de carreira, compartilhar informações e melhores práticas relacionadas à formulação e implementação de políticas públicas.

Também foi possível observar pelo relato que a carreira de gestores governamentais em Mato Grosso apresenta alguns elementos para caracterizá-la como um grupo diferenciado no Poder Executivo estadual. Vale citar o trânsito na área burocrática, política e acadêmica; o elevado percentual de titulação em nível de mestrado/doutorado; a presença no nível estratégico dos órgãos e entidades; as ocupações de cargos comissionados em alto nível e várias áreas diferentes; entretanto, ainda faltam diversos elementos para identificá-la como uma elite burocrática ou administrativa; mas as mudanças promovidas ao longo do atual governo criam um terreno propício para avanço nesse sentido.

A escassez de referenciais teóricos que tratem das carreiras estaduais de gestores governamentais, os precários arquivos públicos e a dificuldade de estruturar com clareza a opinião dos profissionais entrevistados acerca do espaço institucional ocupado pela carreira no âmbito da máquina administrativa do Estado de Mato Grosso foram fatores restritivos que dificultaram os avanços ainda maiores da presente pesquisa.

Por fim, sugere-se que pesquisas futuras sejam realizadas no sentido de verificar as relações entre a arena política e o campo de atuação dos profissionais da carreira de gestores governamentais de Mato Grosso, de modo a procurar identificar as convergências e os atritos entre os profissionais e os políticos num Estado de tradições patrimoniais. 


\section{Referências bibliográficas}

ABRUCIO, Fernando Luiz. Trajetória recente da gestão pública brasileira: um balanço crítico e a renovação da agenda de reformas. RAP. Revista Brasileira de Administração Pública, v. 1, p. 77-87, 2007. Disponível em: <http://dx.doi.org/10.1590/S0034$76122007000700005>$ Acesso em: 09 set. 2014.

ARAúso, Vinicius de Carvalho. Estado de reforma: Reflexões sobre a experiência de reforma do Estado de Mato Grosso. Cuiabá: TantaTinta, 2005.

Paz sobre fogo cerrado (1945-2002). Cuiabá: EdUFMT, 2012.

BAtISTA JR., Paulo Nogueira. Nacionalismo e desenvolvimento. Novos estud. CEBRAP [online]. 2007, n.77, p. 29-35. Disponível em: <http://dx.doi.org/10.1590/ S0101-33002007000100002>. Acesso em: 24 ago. 2014.

Bresser-PereirA, Luiz Carlos. Burocracia pública e reforma gerencial. Revista do Serviço Público de 1937 a 2007. Ed. Especial. Brasilia: ENAP, 2007. p. 29-48.

Dimaggio, Paul J.; Powell, Walter W. A Gaiola de Ferro. Revisitada: isomorfismo institucional e racionalidade coletiva nos campos organizacionais. Revista de Administração de Empresas, v. 45, n. 2, p. 74-89, abr./jun. 2005.

FerreIRA, Afonso; SILVA, Jomara. Realinhamento de Competências. In: MARINI, Caio; MARTINS, Humberto F.; VilhenA, Renata; e BARreto, Tadeu (Org). O Choque de Gestão em Minas Gerais: Políticas da Gestão Pública para o Desenvolvimento. Belo Horizonte, Editora UFMG, 2006.

GRAEF, Aldino. Origens e fundamentos da carreira de Gestor Governamental. Revista de Políticas Públicas e Gestão Governamental, Brasília, v. 9, n. 1, p.7-24, jan./jun. 2010. Disponível em: <http://www.anesp.org.br/files/ResPvblica_9.1.pdf> Acesso em: 09 set. 2014.

MotA, Maria Martha; Coelho, Fernando de Souza; GoMES, Thiago Von Zeidler; TEIXEIRA, Caio Penko. Especialista em políticas públicas e gestão governamental: Uma descrição da carreira nos estados da Bahia, Goiás, Mato Grosso, Minas Gerais, Rio de Janeiro e São Paulo. Revista Gestão \& Políticas Públicas, São Paulo, v. 1, n. 1, 2011. Disponível em: <http://each.uspnet.usp.br/rgpp/index.php/rgpp/article/ view/9>. Acesso em: 01 set. 2014.

Julio Cezar de Lara

É Especialista em Administração Pública pela Universidade Federal de Mato Grosso (UFMT). Atua como Gestor Governamental no Governo de Mato Grosso. Contato: juliolara@seplan.mt.gov.br

Kelliton Rodrigues de Souza

É Especialista em Gestão Pública e Responsabilidade Fiscal pela Escola Superior Aberta do Brasil (ESAB). Atua como Gestor Governamental no Governo de Mato Grosso. Contato: kellitonsouza@seplan.mt.gov.br

Maria Stella Lopes Okajima Conselvan

É Especialista em Gestão Pública pelo Instituto Cuiabano de Educação (ICE-MT). Atua como Gestora Governamental no Governo de Mato Grosso. Contato: mariaconselvan@seplan.mt.gov.br

Vinícius de Carvalho Araújo

É Mestre em História Política pela Universidade Federal de Mato Grosso (UFMT) Atua como Gestor Governamental no Governo de Mato Grosso. Contato: viniciusaraujo@seplan.mt.gov.br 


\section{RSP}

